\title{
PENGARUH PENERAPAN PENDEKATAN SCIENTIFIC DITINJAU DARI MINAT BELAJAR TERHADAP HASIL BELAJAR SISWA DI SD MUHAMMADIYAH I KUDUS
}

\author{
Masturi, FinaFakhriyah, Sumaji, Mila Roysa \\ fina.fakhriyah@umk.ac.id \\ Fakultas Keguruan dan Ilmu Pendidikan \\ Universitas Muria Kudus
}

\begin{abstract}
This studyaims to determinewhich onehas abetterlearning outcomes, students withlearning interestis high,medium or lowinthe fourth grade studentsof SD Muhammadiyah1Kuduson the application ofscientificapproach. This research isquasiexperimental researchdesign withtwowayANOVAwith $2 \times 3$ factorial design. Test datawere analyzed bytwowayANOVAwith the resultsFobs $>\mathrm{Fa}=122.63>3.0$. The results showedthat the threeinterestin learning(high,medium, low) studentshave different effectson learning achievementbetweenthe experimental classwithgradecontrol.
\end{abstract}

Keywords: scientificapproach, interest inlearning

\begin{abstract}
ABSTRAK
Penelitian ini bertujuan untuk mengetahui manakah yang mempunyai hasil belajar lebih baik, siswa dengan minat belajar tinggi, sedang atau rendah pada siswa kelas IV SD Muhammadiyah 1 Kudus pada penerapan pendekatan scientific. Jenis penelitian ini merupakan penelitian eksperimen semu dengan desain anava 2 jalan dengan rancangan faktorial $2 \times 3$. Data hasil tes dianalisis dengan uji anava 2 jalan dengan hasil $F_{o b s}>F_{a}=$ 122,63 > 3,0. Hasil penelitian menunjukkan bahwa ketiga minat belajar (tinggi, sedang, rendah) siswa memberikan efek yang berbeda terhadap prestasi belajar antara kelas eksperimen dengan kelas kontrol.
\end{abstract}

Kata Kunci: Pendekatan scientific, minat belajar 
Pendidikan memegang peranan penting dalam upaya peningkatan dan pengembangan sumber daya manusia. Menurut Adrian (2004) pendidikan adalah usaha sadar untuk menumbuhkembangkan potensi Sumber Daya Manusia (SDM) melalui kegiatan pembelajaran.Pembelajaran di Sekolah Dasar menjadi landasan untuk pengembangan pendidikan pada jenjang berikutnya. Oleh karena itu pembelajaran ditingkat SD haruslah mampu berfungsi mengembangkan potensi diri siswa secara optimal. Hal ini akan terwujud ketika siswa termotivasi mengikuti proses pembelajaran.

Prestasi belajar siswa dipengaruhi dua faktor utama yaitu faktor internal dalam diri siswa dan faktor eksternal diluar diri siswa. Salah satu faktor internal yang mempengaruhi yaitu minat siswa. Minat setiap siswa untuk menerima materi yang diberikan oleh guru berbeda-beda, selain itu setiap siswa juga memiliki karakteristik yang berbeda. Tanpa minat belajar, keaktifan dan interaksi siswa tidak optimal sehingga prestasi belajar siswa kurang.

Peran guru untuk membangkitkan minat belajar siswa sangat penting. Guru harus mampu menggunakan model-model pembelajaran yang inovatif supaya dapat meningkatkan minat belajar siswa. Pengaruh minat belajar sangat menentukan kegiatan siswa dalam mengikuti proses pembelajaran. Siswa dengan minat belajar tinggi cenderung untuk aktif dalam interaksi belajar dikelas.

Pelaksanaan proses pembelajaran dalam kerangka kurikulum 2013 sebaiknya menggunakan pembelajaran tematik terpadu dengan pendekatan scientific. Dalam arti luas pembelajaran terpadu meliputi pembelajaran yang terpadu dalam satu disiplin ilmu, terpadu antarmata pelajaran, serta terpadu dalam dan lintas peserta didik
(Fogarty, 1991).Dengan pembelajaran tematik siswa diharapkan dapat membangkitkan minat belajar siswa tanpa membeda-bedakan ketertarikannya pada tiap mata pelajaran. Hal ini sesuai dengan hasil penelitian yang telah dilakukan oleh Sumiatun (2006) yang menunjukkan bahwa penerapan pembelajaran tematik lebih memudahkan guru dalam memilih cara mengajar sesuai dengan kompetensi yang dimiliki oleh siswa. Kompetensi yang dimiliki siswa akan mempengaruhi keberhasilan siswa dalam menyerap materi pembelajaran.

Proses pembelajaran dengan pendekatan saintifik dilakukan melalui proses mengamati, menanya, mencoba, mengasosiasi, dan mengomunikasikan. Lima pengalaman belajar ini diimplementasikan ke dalam model atau strategi pembelajaran, metode, teknik, maupun taktik yang digunakan.

Dengan pendekatan scientific, siswa akan terlibat langsung dalam proses pembelajaran sehingga minat belajar siswa secara langsung akan terbentuk.Penjelasan Sudarwan (2013) tentang pendekatan scientific bahwa pendekatan ini bercirikan penonjolan dimensi pengamatan, penalaran, penemuan, pengabsahan, dan penjelasan tentang suatu kebenaran. Dengan demikian, proses pembelajaran harus dilaksanakan dengan dipandu nilai-nilai, prinsip-prinsip, atau kriteria ilmiah.

Berdasarkanketerangan di atasminatbelajarsiswadanpendekatan scientific

akanmemberikanpengaruhhasilbelajar.

Siswa yang berminatbelajartinggimenggunakanwakt uluanguntukbertanyakepadatemanatau guru bilabelumjelas, apabilaadapermasalahanselalumencariin formasidaribuku lain yang dapatmembantu. Sedangkansiswa yang minatbelajarnyarendah, siswatersebuthanyamasabodohdansulitu 
ntukmenerimapelajaran,

jarangmengerjakantugas yang diberikan guru,

malasbertanyaapabilapunyapermasalaha ndalambelajardariberbagaimatapelajara

n.Sedangkan pendekatan scientificadalahmerupakansuatupendeka tanpembelajarandimanasiswamengerjak anaktivitassepertimengamati,

menanya,mengolah, menalar, menyajikan, menyimpulkan, danmencipta. Sedangkan model pembelajaranLangsung guru menstransferilmupengetahuankepadasis wa,

sedangkansiswalebihbanyaksebagaipene rima. Dari uraian di atasdanmemperhatikankarakteristikmina tbelajarsiswadan model pembelajaran, dimungkinkanbahwasiswa denganminatbelajartinggi, sedangdanrendahpendekatan scientificmemberikanhasilbelajar yang lebihbaikdaripada model Langsung.

Dengan penerapan pendekatan scientific banyakaktivitas yang dapat dilakukanoleh

siswa.Sehinggamemotivasisiswauntukbi samenemukandanmemahamikonsep dengan pembelajaran tematik. Selain itu, peneliti melihat manakah kategori (tinggi, sedang, rendah) yang berpengaruh pada prestasi belajar.

Permasalahan yang diteliti yaitu; Manakah yang mempunyai hasil belajar lebih baik, siswa dengan minat belajar tinggi, sedang atau rendah pada siswa kelas IV SD Muhammadiyah 1 Kudus?. Tujuan penelitian ini untuk mengetahui manakah mempunyaihasilbelajarlebihbaik, yang siswadenganminatbelajartinggi, sedangataurendahpadasiswakelas IV SD Muhammadiyah 11 Kudus padapenerapanpendekatanscientific.

\section{Metode Penelitian}

Penelitian ini dilaksanakan di

SD Muhammadiyah 1Kudus Jawa
Tengah.Subyekpenelitianadalahsiswake las IV semester gasal TahunAjaran2015/2016.Penelitian ini merupakan penelitian eksperimen semu.Variabelterikatdalampenelitianini adalahprestasi belajar siswapadatemaselalu berhemat energisubtemamacam-macam sumber energi,

sedangkanvariabelbebasnyaadalahpener apanpendekatan scientific.

Sampelpenelitianiniterdiridarikel asIV.b

(kelaseksperimendenganpembelajaranpe ndekatan scientific), kelasIV.a (kelaskontroldengan model pembelajaranlangsung) masingmasingkelasberjumlah 36 siswa.

Data penelitian ini diperoleh dengan teknik tes maupun teknik nontes. Teknik tes dilaksanakan dalam bentuk pretest, postest dan lembar kegiatan siswa. Sedang dengan teknik non-tes diperoleh melalui lembar pengamatan/observasi. Data penelitian yang diperoleh berupa hasil pretest dan postest, hasil angket minat belajar siswa, dan hasil wawancara dengan guru kelas dan beberapa siswa.

Sebelum proses pembelajaran dengan menggunakan pendekatan scientific dilakukan pretest (tes awal) untuk mengetahui sejauh mana pemahaman siswa pada subtema keindahan alam negeriku (muatan IPA, Bahasa Indonesia dan Matematika). Kemudian dilaksanakan pembelajaran dan diakhir proses pembelajaran dalam penelitian ini dilakukan postest. Setelah data diperoleh dari pelaksanaan penelitian, yang dilakukan selanjutnya adalah pengujian terhadap data tersebut. Uji yang dilakukan meliputi uji normalitas, uji homogenitas, uji keseimbangan, uji hipotesis dan uji lanjut pasca anava. Minat belajar siswa diukur dengan memberikan lembar angket minat belajar siswa sebelum melaksanakan pembelajaran. 
Indikator keberhasilan penelitian ini adalah dengan pendekatan scientific daripada sedang maupun rendah dan siswa dengan minat belajar sedang mempunyai hasil belajar lebih baik daripada siswa dengan minat belajar rendah pada siswa kelas IV SD Muhammadiyah 1 Kudus

\section{HASIL DAN PEMBAHASAN}

\section{A. Hasil Penelitian}

a. Uji Normalitas

Hasil uji normalitas pada prestasi belajar siswa pada materi tema

Tabel 1. Rangkuman Hasil Uji Normalitas

\begin{tabular}{|c|c|c|c|c|}
\hline Sumber & $\mathbf{L}_{\mathbf{o b s}}$ & $\mathbf{L}_{\boldsymbol{\alpha}, \mathbf{n}}$ & Keputusan & Kesimpulan \\
\hline $\begin{array}{l}\text { Prestasi belajar dengan } \\
\text { pendekatan } \text { scientific }\left(\mathrm{A}_{1}\right)\end{array}$ & 0,1210 & 0,1645 & $\mathrm{H}_{0}$ diterima & Normal \\
\hline $\begin{array}{l}\text { Prestasi Belajar Dengan Model } \\
\text { pembelajaran Langsung }\left(\mathrm{A}_{2}\right)\end{array}$ & 0,0947 & 0,1618 & $\mathrm{H}_{0}$ diterima & Normal \\
\hline $\begin{array}{l}\text { Prestasi Belajar Pada Minat } \\
\text { Belajar Tinggi }\left(C_{1}\right)\end{array}$ & 0,1012 & 0,2033 & $\mathrm{H}_{0}$ diterima & Normal \\
\hline $\begin{array}{l}\text { Prestasi Belajar Pada Minat } \\
\text { Belajar Sedang }\left(\mathrm{C}_{2}\right)\end{array}$ & 0,1149 & 0,1772 & $\mathrm{H}_{0}$ diterima & Normal \\
\hline $\begin{array}{l}\text { Prestasi Belajar Pada Minat } \\
\text { Belajar Rendah }\left(\mathrm{C}_{3}\right)\end{array}$ & 0,1128 & 0,2288 & $\mathrm{H}_{0}$ diterima & Normal \\
\hline
\end{tabular}

Berdasarkan data dalam Tabel 1. di atas ternyata $\mathrm{H}_{0}$ diterima sehingga dapat disimpulkan bahwa sampelsampel berasal dari populasi yang berdistribusi normal.

\section{b. Uji Homogenitas}

Untuk menguji apakah populasipopulasi dalam penelitian inihomogen siswa dengan minat belajar tinggi mempunyai hasil belajar lebih baik selalu berhemat energi subtema macammacam sumber energi dengan menggunakan metode Lilliefors. Rangkuman uji normalitas dari hasil prestasi belajar siswa pada kelas eksperimen dengan pendekatan scientific, dan kelas kontrol dengan model pembelajaran Langsung dan minat belajar siswa diuraikan pada Tabel 1. sebagai berikut. 


\begin{tabular}{|c|c|c|c|c|}
\hline $\begin{array}{l}\text { Antara prestasi belajar dari kelas n } \\
\text { pembelajaran kelas eksperimen dan } \\
\text { Langsung }\end{array}$ & & & 3,8 & erima \\
\hline $\begin{array}{l}\text { Antara prestasi belajar, minat belajar tinggi, } \\
\text { sedang dan rendah }\end{array}$ & & & & $\mathrm{H}_{0}$ \\
\hline $\begin{array}{l}\text { Berdasarkan Tabel } 2 \text { di atas } \\
\text { nyata } \mathrm{H}_{0} \text { diterima maka dapat } \\
\text { simpulkan bahwa populasi-populasi } \\
\text { empunyai variansi yang homogen. } \\
\text { PengujianHipotesis } \\
\text { Analisis Variansi } \\
\text { Setelah dilakukan uii normalitas }\end{array}$ & \multicolumn{4}{|c|}{$\begin{array}{l}\text { syarat untuk analisis variansi dan } \\
\text { diperoleh semua populasi berdistribusi } \\
\text { normal dan homogen, maka dapat } \\
\text { dilanjutkan uji analisis variansi. Pada } \\
\text { penelitian ini analisis variansi yang } \\
\text { digunakan analisis variansi dua arah } \\
\text { dengan sel tak sama dengan taraf } \\
\text { signifikansi } 0,05 \text { diperoleh hasil sebagai } \\
\text { berikut. }\end{array}$} \\
\hline
\end{tabular}
dan uji homogenitas variansi sebagai

Tabel 3 Rangkuman Analisis Variansi Dua Jalan

\begin{tabular}{|c|c|c|c|c|c|c|}
\hline \multicolumn{7}{|c|}{ Analisis Variansi Dua Jalan } \\
\hline & 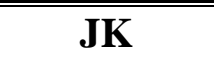 & (dK & RK & 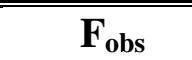 & 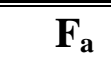 & "Keputusan \\
\hline Model (A) & 9320,6407 & 1 & 9320,6407 & 215,1812 & 3,000 & Ho ditolak \\
\hline $\begin{array}{l}\text { Minat } \\
\text { belajar (B) }\end{array}$ & $\begin{array}{r}10624,175 \\
8\end{array}$ & 2 & 5312,0879 & 122,6377 & 3,000 & Ho ditolak \\
\hline $\begin{array}{l}\text { Interaksi } \\
(\mathrm{AB})\end{array}$ & $-9313,9791$ & 2 & $-4656,9896$ & $-107,5137$ & 2,370 & Ho diterima \\
\hline Galat & 2382,3420 & 55 & 43,3153 & & & \\
\hline Total & $\begin{array}{r}13013,179 \\
4\end{array}$ & 60 & & & & \\
\hline
\end{tabular}

Kesimpulan analisis variansi dua arah dengan sel tak sama berdasarkan Tabel 3adalah :

1) Pada efek utama (A), siswa-siswa yang dikenai dengan model pembelajaran pendekatan scientificdan pembelajaran langsung mempunyai prestasi belajar sub tema macam-macam sumber energi yang berbeda.

2) Pada efek utama (B), ketiga minat belajarsiswa memberikan efek yang berbeda terhadap prestasi belajar siswa.

3) Pada efek interaksi (AB), tidak ada interaksi antara model pembelajaran yang digunakan dan minat belajar siswa terhadap prestasi belajar sub tema macammacam sumber energi.

\section{Uji Lanjut Pasca Analisis Variansi \\ (1) Uji Lanjut Pasca Analisis Variansi}

Uji lanjut pasca analisis variansi dengan metode Scheffe' untuk analisis variansi dua jalan.DariTabel4dengan $\mathrm{F}_{0,05 ; 2 ; 291}=3,00$ sedangkan $\mathrm{DK}=\left\{\mathrm{F}_{1 .-2 \text {. }}\right.$.

$$
\left.\mathrm{F}_{1 .-2 .}>(3-1) \quad \mathrm{F}_{0,05 ; 2 ; 291}=6,00\right\}
$$

diperolehkesimpulanbahwa pada uji Ho: $\mu_{1 .}=\mu_{2 .}$, diperoleh Ho ditolak. Hal ini 
berarti ada perbedaan yang signifikan antara prestasi belajar sub tema macammacam sumber energi pada kelompok siswa yang dikenai pembelajaran dengan pendekatan scientific dan kelompok siswa yang dikenai model pembelajaran langsung.

Tabel 5. Rataan Antar Sel

\begin{tabular}{||l|r|r|r|r||}
\hline \multirow{2}{*}{$\begin{array}{c}\text { Model } \\
\text { Pembelajaran }\end{array}$} & \multicolumn{4}{|c||}{ MINAT BELAJAR } \\
\cline { 2 - 5 } & Tinggi & Sedang & Rendah & Rataan Marginal \\
\hline \hline $\begin{array}{l}\text { Pendekatan } \\
\text { scientific }\end{array}$ & 85,8182 & 66,7143 & 48,5000 & 65,0251 \\
\hline Langsung & 84,5000 & 64,7273 & 51,1667 & 62,9836 \\
\hline Rataan Marginal & 85,2415 & 65,8698 & 49,8846 & \\
\hline
\end{tabular}

Tabel6.RangkumanHasilUjiKomparasiGandaAntarBaris

\begin{tabular}{|c|c|c|c|c|c|c|}
\hline Komparasi & $\left(\overline{X_{\mathrm{s}}}-\overline{X_{J_{2}}}\right)^{2}$ & $\left(\frac{1}{n_{i}}+\frac{1}{n_{i}}\right)$ & RKG & $\mathbf{F}$ & Kritik & Keputusan \\
\hline $\bar{\mu} \mu 1 \mathrm{vs} \mu 2$ & 16,6956 & 0,0626 & 43,3153 & 6,1611 & 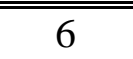 & " Ho ditolak \\
\hline
\end{tabular}

a. Untuk Hipotesis antar kolom antara minat belajar

Dari Analisis Variansi Dua Arah diputuskan bahwa $\mathrm{H}_{0 \mathrm{~B}}$ ditolak, sehingga perlu dilakukan uji lanjut pasca analisis variansi dengan metode Scheffe' untuk analisis variansi dua jalan.

Tabel7.RangkumanHasilUjiKomparasiGandaAntarKolom

\begin{tabular}{|c|c|c|c|c|c|c|}
\hline Komparasi & $\left(\bar{X}_{\bar{i}}-\bar{X}_{j}\right)^{2}$ & $\left(\frac{1}{n_{i}}+\frac{1}{n_{j}}\right)$ & RKG & F & Kritik & Keputusan \\
\hline$\mu 1$ vs $\mu 2$ & 377,2591 & 0,0926 & 43,3153 & 94,0241 & 6 & Ho ditolak \\
\hline$\mu 1$ vs $\mu 3$ & 631,5098 & 0,1026 & 43,3153 & 142,0554 & 6 & Ho ditolak \\
\hline$\mu 2$ vs $\mu 3$ & 32,5664 & 0,0900 & 43,3153 & 8,3538 & 6 & Ho ditolak \\
\hline
\end{tabular}

DariTabel7.dengan $\mathrm{F}_{0,05 ; 2 ; 291}=$ 3,00 sedangkan DK $=\left\{\begin{array}{ll}\mathrm{F}_{.1-2.2} \mid & \mathrm{F}_{.1-.2}\end{array}\right\}$ (3-1) $\left.\mathrm{F}_{0,05 ; 2 ; 291}=6,00\right\}$ diperolehkesimpulansebagaiberikut:

1) Pada uji Ho: $\mu_{.1}=\mu_{.2}$, diperoleh Ho ditolak. Hal ini berarti ada perbedaan yang signifikan antara prestasi belajar sub tema macammacam sumber energi pada kelompok siswa dengan minat belajar tinggi dan kelompok siswa dengan minat belajar sedang.
2) Pada uji Ho: $\mu_{.1}=\mu_{.3}$, diperoleh Ho ditolak. Hal ini berarti ada perbedaan yang signifikan antara prestasi belajar sub tema macammacam sumber energi pada kelompok siswa dengan minat belajar tinggi dan kelompok siswa dengan minat belajar rendah.

3) Pada uji Ho: $\mu_{.2}=\mu_{.3}$, diperoleh Ho ditolak. Hal ini berarti ada perbedaan yang signifikan antara prestasi belajar sub tema macam- 
macam sumber energi pada kelompok siswa dengan minat belajar sedang dan kelompok siswa dengan minat belajar rendah.

b. Untuk Hipotesis komparasi pasca anava antar sel

\section{B. PEMBAHASAN}

Berdasarkan analisis hasil hipotesis dan uji lanjut pasca anava yang telah diuraikan diatas perbedaan prestasi belajar antara siswa yang dikenai pendekatan scientific, dengan pembelajaran langsung. Berdasarkan dari uji pasca anava, diperoleh rataan marginal pendekatan scientific adalah 65,0251 dan pembelajaran langsung adalah 62,9836. Sehingga dapat disimpulkan bahwa prestasi belajar dengan subtema macam-macam sumber energi, siswa yang diajar dengan menggunakan pendekatan scientific mempunyai prestasi belajar yang lebih baik daripada siswa yang dikenai model pembelajaran langsung. Sedangkan pada model pembelajaran langsung proses pembelajaran cenderung berpusat pada guru. Sehingga kemampuan siswa belum terlihat dan cenderung pasif. Hal ini sesuai dengan hasil penelitian Wijayanti (2014) bahwa pendekatan scientific merupakan proses pembelajaran yang dirancang sedemikian rupa agar peserta didik secara aktif mengonstruk konsep, hukum atau prinsip melalui tahapan-tahapan mengamati (untuk mengidentifikasi atau menemukan masalah), merumuskan masalah, mengajukan atau merumuskan hipotesis, mengumpulkan data dengan berbagai teknik, menganalisis data, menarik kesimpulan dan mengomunikasikan konsep, hukum atau prinsip yang telah ditemukan. Hal ini memberikan konsekuensi pada siswa untuk mau mencari tahu, bekerjasama dengan teman, mencari sumber belajar dari lingkungan sekitar. Konsekuensi inilah yang dapat membuat siswa
Dari Analisis Variansi Dua Arah diputuskan bahwa $\mathrm{H}_{0 \mathrm{AB}}$ diterima, maka tidak perlu dilakukan komparasi pasca anava antar sel.

tertarik untuk terlibat dalam proses pembelajaran.

Hasil analisis variansi dua jalan disimpulkan bahwa siswa dengan minat belajar tinggi mempunyai hasil belajar yang lebih baik daripada siswa dengan minat belajar sedang, maupun rendah dan siswa dengan minat belajar sedang mempunyai hasil belajar yang lebih baik daripada siswa dengan minat belajar rendah, siswa yang mempunyai minat yang tinggi sangat senang saat mengikuti pelajaran, saat belajar secara berkelompok, sangat perhatian saat mengikuti pelajaran, dan saat diskusi pelajaran, siswa dengan minat belajar sedang cukup senang saat mengikuti pelajaran, belajar secara berkelompok, cukup perhatian saat mengikuti pelajaran, dan saat diskusi pelajaran. Sedangkan siswa dengan minat belajar rendah kurang senang saat mengikuti pelajaran, saat belajar secara berkelompok, kurang perhatian saat mengikuti pelajaran, dan saat diskusi pelajaran. Hal ini sesuai pendapat Aritonang (2008) yang menyatakan bahwa faktor yang paling utama yang menentukan apakah siswa akan berminat dan termotivasi untuk belajar adalah faktor dari guru. Karena guru sebagai fasilitator harus mampu memilih dan mengolah metode, strategi dan motif mengajar yang dapat meningkatkan minat dan motivasi belajar para siswa dan guru terlibat langsung dalam proses belajarmengajar.

Siswa dengan minat belajar tinggi, sedang, dan rendah, pada kelas eksperimen yang dikenai pendekatan scientific memiliki prestasi belajar lebih 
baik daripada yang diajar dengan pembelajaran langsung. Hal ini diperkuat dengan pendapat Slameto (2003:180) yang menyatakan bahwa minat besar pengaruhnya terhadap belajar karena bila bahan pelajaran yang

\section{PENUTUP}

Berdasarkan landasan teori dan didukung oleh analisis data serta mengacu pada perumusan masalah yang telah diuraikan pada bab-bab sebelumnya, maka dapat di simpulkan sebagai berikut.;

1) Pembelajaran dengan pendekatan scientific memberikan prestasi belajar pada subtema macam-macam sumber energi yang lebih baik daripada model pembelajaran langsung.

\section{DAFTAR PUSTAKA}

A Wijayanti. 2014. Pengembangan AutenticAssesment Berbasis Proyek Dengan Pendekatan Saintifik Untuk Meningkatkan Keterampilan Berpikir Ilmiah Mahasiswa. Jurnal Pendidikan IPA Indonesia 3 (2) (2014) 102108

Adrian. 2004. Metode Mengajar Berdasarkan Tipologi Belajar Siswa. online at. http://researchengines.com/art0565.html.diakses 12 Desember 2015.

Aritonang, Keke T. 2008. Minat dan Motivasi dalam Meingkatkan Hasil Belajar Siswa. Jurnal Pendidikan Penabur. No.10 Tahun ke-7 (2008) 11-21.

Astutik, Windi. 2013. Penerapan Model Pembelajaran Problem Based Instruction (PBI) dengan Media dipelajari tidak sesuai dengan minat siswa maka siswa tidak akan belajar dengan sebaik-baiknya, karena tidak ada daya tarik baginya sehingga hasil belajar yang diperoleh tidak maksimal.

2) Siswa dengan minat belajar tinggi mempunyai prestasi belajar subtema macam-macam sumber energi yang lebih baik daripada siswa dengan minat belajar sedang maupun rendah, dan siswa dengan minat belajar sedang mempunyai prestasi belajar subtema macam-macam sumber energi yang lebih baik daripada siswa dengan minat belajar rendah.

Permainan Kartu Soal disertai Jawaban pada Pembelajaran Fisika di SMA. Jember. On line athttp://library.unej.ac.id/client/en _US/default/search/asset/569?dt=1 ist [accesed 21 Agustus 2014].

Ayse, O \& Sertac, A. 2011. Overviews On Inquiry Based and Pro blem Based Learning Methods.Westerrn Anatolia Journal of Educational Science. Special Issue: 303-309

Sardiman. 2003. Interaksi dan Motivasi Belajar Mengajar. Jakarta: RajaGrafindo Persada.

Sudarwan. 2013. Pendekatan-pendekatan Ilmiah dalam Pembelajaran, Makalah pada Workshop Kurikulum. Jakarta.

Slameto. 2003. Belajar dan Faktor-faktor yang Mempengaruhinya. Jakarta: PT Rineka Cipta. 